Hawa Keïta MD, Gilles Peytavin PhD, Olivier Giraud MD, Jacqueline Silleran MD, Lanto Rahoeliarivaraux MD, Jean-Marie Desmonts MD, Jean Mantz MD PhD

\section{Aging prolongs recov- ery of psychomotor functions at emergence from propofol-alfentanil anaesthesia}

Purpose: To compare recovery of psychomotor function in elderly and young surgical patients at emergence from propofol-alfentanil anaesthesia.

Methods: Ten elderly ( $>70 \mathrm{yr}$ ) and 10 younger $(<40 \mathrm{yr}$ ) patients scheduled for orthopaedic surgery of less than three hours, were anesthetized with nitrous oxide, propofol and alfentanil. Propofol and alfentanil cumulative doses, time from cessation of propofol infusion to eye opening (EO) on verbal command and to extubation were recorded. Psychomotor performance was assessed by the Mini-Mental State (MMS) performed the day prior to surgery and postoperatively at 30,60, and I20 min. following extubation. Propofol blood concentrations were measured at EO and at each MMS task.

Results: Elderly patients were comparable with young patients for preoperative MMS scores, surgery and anaesthesia duration, propofol and alfentanil cumulative doses. Postoperative MMS scores were lower at 30,60 and $120 \mathrm{~min}$. in elderly patients. Propofol blood concentrations were not different between elderly and young patients at $\mathrm{EO}, 30,60$ and $120 \mathrm{~min}$.

Conclusion: Psychomotor performance is impaired in elderly compared with young patients at emergence from propofol- alfentanil anaesthesia. These differences are not likely to be related to propofol accumulation in elderly subjects.

Objectif : Comparer la récupération de la fonction psychomotrice chez des patients âgés et de jeunes patients lors du réveil après une anesthésie au propofol et à l'alfentanil.

Méthode : Dix patients âgés ( $>70$ ans) et 10 jeunes patients (< 40 ans), dont la chirurgie orthopédique de moins de trois heures avait été prévue, ont reçu une anesthésie avec du protoxyde d'azote, du propofol et de l'alfentanil. On a enregistré les doses cumulatives de propofol et d'alfentanil, le temps entre l'arrêt de la perfusion de propofol et l'ouverture des yeux (OY), d'après une commande verbale, et le moment de l'extubation. Le rendement psychomoteur a été évalué par le test MMS de Folstein et coll. (Mini-Mental State) administré le jour précédent la chirurgie et, après la chirurgie, 30,60 et 120 min. après l'extubation. Les concentrations sanguines de propofol ont été mesurées à I'OY et à chaque tâche du test MMS.

Résultats : Les rendements au MMS préopératoire', la durée de la chirurgie et de l'anesthésie et les doses cumulatives de propofol et d'alfentanil étaient comparables entre les jeunes patients et les patients âgés. Les rendements MMS postopératoires ont été plus bas à 30,60 et 120 min chez les patients âgés. Les concentrations sanguines de propofol n'étaient pas différents entre les deux groupes de patients à l'OY, et à 30,60 et 120 min.

Conclusion : Le rendement psychomoteur est altéré chez les patients âgés par rapport aux jeunes patients au moment du réveil après l'anesthésie au propofol et à l'alfentanil. On ne peut probablement pas relier ces différences à l'accumulation de propofol chez les patients âgés.

From the Department of Anaesthesiology and Critical Care and the Department of Toxicology, Hospital Bichat, and INSERM U 408, Paris, France.

Supported by INSERM and the Délégation à la Recherche Clinique, Assistance Publique des Hôpitaux de Paris, Paris, France (grant AOM 95024).

Address correspondence to: Dr H. Keïta, Department of Anaesthesiology and Critical Care, Hospital Bichar, 46 rue Henri Huchard, 75018 Paris, France. Phone: 33-140-25-83-54; Fax: 33-142-28-99-96; E-mail: hanemaal@club-internet.fr

Presented in part at the Annual Meeting of the American Society of Anesthesiologists, New Orleans, Louisiana, October 19-23, 1996.

Accepted for publication September 26, 1998 
A GING is associated with a decrease in requirement for intravenous anaesthetics. ${ }^{1,2}$ However, little is known of the influence of aging on the time-course of recovery of cognitive functions after anaesthesia and surgery. In a previous study, neuropsychological function was found to be impaired on the first postoperative day following intraabdominal surgery, but this cognitive dysfunction was transient and similar in young and elderly patients. ${ }^{3}$ In the present study we compared psychomotor performance at emergence from anaesthesia between young and elderly patients undergoing elective orthopaedic surgery under propofol-alfentanil anaesthesia.

\section{Methods}

After institutional approval and written informed consent, 20 patients, ASA 1 or 2 physical status scheduled for elective orthopaedic surgery $(<3 \mathrm{hr})$ were prospectively allocated to an elderly ( $>70 \mathrm{yr}$ ) or young $(<40$ yr) group. Exclusion criteria were outpatients, unstable angina, severe myocardial dysfunction, a history of anaphylactic reaction during previous anaesthesia and the inability to perform MMS (0 - 32 score $)^{4}$ (see appendix) because of language barrier or a score $<25 / 32$.

Patients received no premedication and atropine was not administered, since anticholinergic medication has been associated with postoperative confusion. ${ }^{5}$ Anaesthesia was induced by propofol $\left(20 \mathrm{mg} \cdot \mathrm{kg}^{-1} \cdot \mathrm{hr}^{-1}\right.$ for $5 \mathrm{~min}$.) and $5 \mu \mathrm{g} \cdot \mathrm{kg}^{-1}$ alfentanil. Succinylcholine $\left(0.08 \mathrm{mg} \cdot \mathrm{kg}^{-1}\right)$ was used to facilitate orotracheal intubation, and no other neuromuscular blocking agent was given. Mechanical ventilation $\left(0_{2} 60 \%-\mathrm{N}_{2} \mathrm{O} 40 \%\right)$ was initiated to keep $\mathrm{P}_{\mathrm{ET}} \mathrm{CO}_{2}$ between 30 and $35 \mathrm{mmHg}$. Esophageal temperature was controlled to $37^{\circ} \mathrm{C}$ by surface warming (Bair Hugger devices). The maintenance rate of propofol infusion was based on a stepwise infusion regimen (12 mg.kg-1. $\mathrm{hr}^{-1}$ for $10 \mathrm{~min}$., and 6 $\mathrm{mg} \cdot \mathrm{kg}^{-1} \cdot \mathrm{hr}^{-1}$ until the end of the procedure). These infusion rates were modified to maintain MAP and/or HR within $-30 \%$ and $-10 \%$ of the baseline values when appropriate. Additional alfentanil boluses, $5 \mu \mathrm{g} \cdot \mathrm{kg}^{-1}$, were given when necessary except during the last 30 $\mathrm{min}$ of anaesthesia. Propofol infusion was stopped after skin closure and tracheas were extubated when the spontaneous breathing was restored (respiratory rate > $10 \mathrm{~min}^{-1}$ ).

The data recorded were age, weight, pre-, intraand postoperative blood pressure and $\mathrm{HR}$, propofol and alfentanil cumulative doses, time from cessation of propofol administration to EO and extubation, duration of surgery and anaesthesia defined as the times from induction of anaesthesia to skin closure and extubation, respectively. Psychomotor performance was assessed by the MMS the day prior to surgery. The MMS, sedation and pain scores (see appendix) were performed in the postoperative care unit, at 30,60 , and $120 \mathrm{~min}$ after extubation. At these times and at $\mathrm{EO}$, five $\mathrm{ml}$ arterial blood samples were drawn for determination of propofol blood concentration. Postoperative analgesia was achieved with intravenous propacetamol and morphine was not given. The occurrence of nausea and vomiting, hypoxaemia (one or more episodes of oxygen saturation $\mathbf{8 0 \%}$ for two minutes) and severe hypotension (MAP decrease > $30 \%$ of the preinduction value over five minutes) was also noted.

\section{Statistics}

Results are expressed as mean \pm SEM. Statistical analysis was performed using the MannWhitney-Wilcoxon test, a $P$ value $<0.05$ being considered significant.

\section{Results}

Patients were comparable for weight and duration of anaesthesia and surgery. No difference was observed in propofol and alfentanil total intraoperative requirements between the groups (Table I). No major difference was observed between the two groups with respect to $\mathrm{HR}$ or MAP (Table II).

Postoperative MMS scores were lower in elderly patients at 30,60 and $120 \mathrm{~min}$. after extubation, while the sedation scores were similar between the two groups at the same times (Table III). Pain scores at these times were also comparable. No major side effect, particularly nausea or vomiting, was observed in the recovery room in the two groups. Propofol blood concentrations were not different between the two groups at any time.

TABLE I Demographic and intraoperative DATA.

\begin{tabular}{llll}
\hline & Elderly & Young & $P$ \\
\hline Number (n) & 10 & 10 & \\
Age (n) & $76 \pm 2$ & $29 \pm 1$ & 0.0004 \\
Weight (kg) & $67 \pm 3$ & $65 \pm 4$ & NS \\
Duration of surgery (min) & $99 \pm 21$ & $59 \pm 13$ & NS \\
Duration of anaesthesia (min) & $118 \pm 19$ & $76 \pm 16$ & NS \\
P total dose (mg $\left.\mathrm{kg}^{-1} \cdot \mathrm{hr}^{-1}\right)$ & $10 \pm 1$ & $13 \pm 2$ & $\mathrm{NS}$ \\
A total dose $\left(\mathrm{mg} \cdot \mathrm{kg}^{-1} \cdot \mathrm{hr}^{-1}\right)$ & $24 \pm 6$ & $36 \pm 6$ & $\mathrm{NS}$ \\
Time to EO (min) & $18 \pm 5$ & $17 \pm 3$ & $\mathrm{NS}$ \\
Time to extubation (min) & $19 \pm 5$ & $17 \pm 3$ & $\mathrm{NS}$ \\
\hline
\end{tabular}

Data: mean $\pm S E M$

$P=$ propofol, $\mathrm{A}=$ alfentanil, $\mathrm{EO}=$ eye opening. 
TABLE II Intraoperative hemodynamic variations in young and elderly patients.

\begin{tabular}{|c|c|c|c|c|c|c|c|c|}
\hline \multirow[b]{2}{*}{ Time } & \multicolumn{3}{|c|}{ Elderly } & \multicolumn{5}{|c|}{ Young } \\
\hline & $\begin{array}{c}M A P \\
(m m H g)\end{array}$ & $\begin{array}{c}P \\
\text { vs control } \\
\text { for } M A P\end{array}$ & $\begin{array}{c}H R \\
\left(b \cdot \mathrm{min}^{-1}\right)\end{array}$ & $\begin{array}{c}P \\
\text { ps control } \\
\text { for } H R\end{array}$ & $\begin{array}{c}M A P \\
(m m H g)\end{array}$ & $\begin{array}{c}P \\
\text { vs control } \\
\text { for map }\end{array}$ & $\begin{array}{c}H R \\
\left(b \cdot \mathrm{min}^{-1}\right)\end{array}$ & $\begin{array}{c}P \\
\text { vs control } \\
\text { for } H R\end{array}$ \\
\hline Control & $111 \pm 7$ & & $79 \pm 3$ & & $94 \pm 4$ & & $76 \pm 6$ & \\
\hline$+2 \mathrm{~min}$ & $86 \pm 7$ & 0.02 & $75 \pm 4$ & NS & $80 \pm 3$ & 0.009 & $68 \pm 5$ & 0.03 \\
\hline$+4 \mathrm{~min}$ & $78 \pm 7$ & 0.007 & $70 \pm 4$ & NS & $76 \pm 4$ & 0.005 & $69 \pm 7$ & 0.01 \\
\hline$+6 \mathrm{~min}$ & $84 \pm 4$ & 0.005 & $68 \pm 4$ & 0.02 & $84 \pm 4$ & 0.02 & $72 \pm 5$ & NS \\
\hline$+10 \mathrm{~min}$ & $81 \pm 4$ & 0.01 & $72 \pm 4$ & NS & $78 \pm 8$ & 0.01 & $80 \pm 10$ & NS \\
\hline$+15 \mathrm{~min}$ & $87 \pm 5$ & NS & $72 \pm 5$ & NS & & & & \\
\hline Incision & $84 \pm 5$ & 0.019 & $65 \pm 4$ & 0.011 & $78 \pm 6$ & 0.005 & $63 \pm 4$ & 0.028 \\
\hline$+2 \min$ & $84 \pm 3$ & 0.012 & $63 \pm 4$ & 0.007 & $85 \pm 7$ & NS & $66 \pm 4$ & NS \\
\hline$+5 \min$ & $83 \pm 4$ & 0.019 & $66 \pm 6$ & 0.03 & $83 \pm 8$ & NS & $66 \pm 4$ & NS \\
\hline$+10 \mathrm{~min}$ & $78 \pm 5$ & 0.012 & $67 \pm 5$ & NS & $85 \pm 7$ & NS & $60 \pm 4$ & 0.007 \\
\hline Extubation & $99 \pm 7$ & NS & $72 \pm 6$ & NS & $97 \pm 5$ & NS & $87 \pm 6$ & NS \\
\hline$+10 \mathrm{~min}$ & $100 \pm 7$ & NS & $72 \pm 5$ & NS & $91 \pm 4$ & NS & $80 \pm 7$ & NS \\
\hline$+30 \mathrm{~min}$ & $101 \pm 6$ & NS & $71 \pm 4$ & NS & $94 \pm 4$ & NS & $66 \pm 4$ & 0.02 \\
\hline$+60 \mathrm{~min}$ & $101 \pm 5$ & NS & $71 \pm 4$ & NS & $89 \pm 4$ & NS & $66 \pm 4$ & NS \\
\hline$+120 \mathrm{~min}$ & $96 \pm 3$ & NS & $76 \pm 6$ & NS & $86 \pm 3$ & NS & $71 \pm 4$ & NS \\
\hline
\end{tabular}

Data are expressed as mean \pm SEM

$\mathrm{MAP}=$ mean arterial pressure, $\mathrm{HR}=$ heart rate, control values were obtained just before induction of anaesthesia

TABLE III Psychomotor performance of patients at emergence from anacsthesia and propofol blood concentrations.

\begin{tabular}{lllll}
\hline & & Elderly & roung & $P$ \\
\hline SS (0-4) & $30 \mathrm{~min}$ & $3 \pm 0.3$ & $4 \pm 0.2$ & NS \\
& $60 \mathrm{~min}$ & $3 \pm 0.2$ & $4 \pm 0.2$ & NS \\
& $120 \mathrm{~min}$ & $4 \pm 0.2$ & $4 \pm 0.2$ & NS \\
MMS (0-32) pre-op & $30 \pm 1$ & $31 \pm 0.4$ & NS \\
$30 \mathrm{~min}$ & $16 \pm 5$ & $30 \pm 1$ & 0.018 \\
& $60 \mathrm{~min}$ & $25 \pm 3$ & $31 \pm 0.5$ & 0.012 \\
& $120 \mathrm{~min}$ & $26 \pm 2$ & $31 \pm 0.4$ & 0.011 \\
P blood conc. (ng. ml & -1 ) EO & $1560 \pm 101$ & $1717 \pm 305$ & NS \\
& $30 \mathrm{~min}$ & $1038 \pm 223$ & $1467 \pm 178$ & NS \\
$60 \mathrm{~min}$ & $736 \pm 115$ & $844 \pm 95$ & NS \\
& $120 \mathrm{~min}$ & $557 \pm 146$ & $538 \pm 50$ & NS \\
\hline
\end{tabular}

Data: mean $\pm S E M$

SS = sedation scores, MMS = Mini Mental State, P. blood conc. = propofol blood concentrations, $E O=$ cye opening.

\section{Discussion}

The main observation made in this study was that psychomotor performance in elderly and young patients differed at the time of emergence from propofol-alfentanil anaesthesia.

Several hypotheses can be proposed to explain this observation. Age-related differences in sensitivity to alfentanil seem unlikely, since alfentanil pharmacodynamics have been found to be similar in elderly and in younger patients. ${ }^{6}$ Also, postoperative hypotension and hypoxaemia, which could contribute to confusion, ${ }^{5}$ were not noted in the postoperative care unit. Pain management was standardized and was unlikely to have influenced patient outcome in this study.

It could be argued that elderly patients exhibited altered postoperative psychomotor performances because they were maintained at higher intraoperative blood concentrations. However, propofol cumulative doses were not different between the two groups. Although we did not use the bispectral index of the EEG to measure depth of anaesthesia, no differences in intraoperative hemodynamic variations were observed between groups. A slower clearance of propofol in the elderly group is also not supported by our data since no elevation of arterial propofol blood concentrations was observed in patients aged $>70 \mathrm{yr}$ at EO and at each MMS trial.

More likely, differences in the response of elderly patients to the same effect site concentration could contribute to this postoperative cognitive dysfunction. Interestingly, elderly-related changes in the sensitivity of specific carriers located on presynaptic GABA (a major target of anesthetics in the brain) nerve endings have been recently demonstrated in the rat. ${ }^{7}$ It can be speculated that these or other related pharmacodynamic responses to propofol might apply to elderly patients.

In conclusion, our results support the hypothesis that aging alters recovery of psychomotor function at emergence from propofol-alfentanil anaesthesia. 


\section{Acknowledgment}

Authors thank Dr Frédérique Servin for insightful discussion.

\section{References}

1 Muravchik S. Effect of age and premedication on thiopental sleep dose. Anesthesiology 1984; 61: 333-6.

2 Jacobs JR, Reves JG, Marty J, White WD, Bai SA, Smith $L R$. Aging increases pharmacodynamic sensitivity to the hypnotic effects of midazolam. Anesth Analg 1995; 80: 143-8.

3 Chung F, Seyone C, Dyck B, et al. Age-related cognitive recovery after general anesthesia. Anesth Analg 1990; 71: 217-24.

4 Anthony JC, LeResche L, Niaz U, von Korff MR, Folstein MF. Limits of the 'Mini-Mental State' as a screening test for dementia and delinum among hospital patients. Psychol Med 1982; 12: 397-408.

5 O'Keeffe ST, Ni Chonchubbair Á. Postoperative delirium in the elderly. Br J Anaesth 1994; 73: 673-87.

6 Lemmens HJM, Bunn AGL, Bovill JG, Hennis PJ. Pharmacodynamics of alfentanil as a supplement to nitrous oxide anaesthesia in the elderly patient. $\mathrm{Br} \mathbf{J}$ Anaesth 1988; 61: 173-9.

7 Keita H, Lasocki S, Henzel-Rouellé D, Desmonts J-M, Mantz J. Aging decreases the sensitivity of the GABA carrier to propofol and etomidate. $\mathrm{Br}$ J Anaesth 1998; 81: 249-50.

\section{Appendix}

Modified version of "Mini-Mental State" evaluation

\section{Score}

Orientation:

/ 5 *Wat is the (year) (season) (date) (day) (month)?

/ 4 *Where are we (state) (town) (hospital) (ward)?

Recall:

/4 * Anterograde amnesia: look at 4 pictures taken out of a children's game of "memory", 1 every second. 5 minutes later, find the pictures amongst 20 others.

/ 3 * Retrograde amnesia: On the first evaluation, the patient memorizes any 3 events he chooses (eg: I came to the hospital in a blue taxi; the nurses are kind, my room mate snores ... ). On the following evalutions, he is asked to recall them.

\section{Attention:}

/ 2 * Spell backwards a simple five letters word (a different one every time).
0 if no response

1 if incorrect

2 if correct

Reasoning:

/ 5 * look at a paper on which are written 2 letters (eg: A-B) and answer by true or false the following sentences:

$A$ is after $B \quad B$ is before $A$

$B$ is not followed by $A$ A is before $B$

$A$ is not before $B$

(letters and sentences are different every time)

\section{Language:}

12 * Name two usual objects (pen, key...)

12 * Repeat the following: "no ifs, ands or buts" ( 0 if does not repeat, 1 if non accurate, 2 if accurate)

/ * Read and obey a simple command (ex: CLOSE YOUR EYES)

/ 2 Write down the previous command

$\angle 2$ * copy a simple drawing

132 Total score

Pain score: $0=$ no pain, $I=$ mild, $2=$ moderate and 3 $=$ severe.

Sedation score: $0=$ asleep, not arousable, $I=$ asleep, but arousable, 2 = drowsy, 3 = awake and quiet calm, $4=$ fully awake and responsive. 